Avrasya Terim Dergisi, 2021, 9 (2): 12 - 26

\title{
ODUN ANATOMİSİ KİTAPLARINDA YAŞANILAN TERİM KARMAŞASI
}

\author{
Kamile Tirak Hizal ${ }^{1}$ \\ 1) Ormancılık ve Orman Ürünleri Programı, Ormancılık Bölümü, Ormancılık Meslek Yüksekokulu, Düzce Üniversitesi, Düzce, \\ Elmek: kamiletirak@duzce.edu.tr ORCID: 0000-0001-7114-6320
}

\section{Özet}

Odunun anatomik yapısı birçok bilim dalları içerisinde geçmekte ve farklı kaynaklarda bölümler halinde yer almıştır. Ülkemizde bugüne kadar odunun anatomik özelliklerinin anlatıldığı Türkçe dilinde sadece 5 kitap yazılmıştır. Kitaplar; gerek çeviri gerekse yapılmış çalışmalar ışı̆̆ında yazılmış olup içerdiği terimler, mevcut biyoloji terimlerinden ya da, doğrudan çevrildiği dilden doğrudan alınmış, çevrildiği dilden dilimizde okunduğu gibi ya da yazan tarafindan oluşturulma şeklinde kullanılmıştır. Bu çalışmada mevcut kaynaklarda karşılaşılan kavramlara verilmiş farklı terimler tespit edilerek meydana gelen karmaşaya dikkat çekilmiştir. İnceleme sonucu 70 adet terimde terimsel farkllik ve 7 adet terimde de yazım farklılı̆ına rastlanmıştır. Mevcut karmaşaya yol açan terimlerin tespit edilmesi ile bu konuya dikkat çekilmiş, terimlerin kullanımı konusunda ilgili bilim insanları ile birlikte ortak karar verilmesi ve çalışmaların başlatılması konusunda önerilerde bulunulmuştur.

Anahtar Kelimeler: Odun Anatomisi, Terim, Kavram

\section{THE TERM CONFLICT IN WOOD ANATOMY BOOKS}

\section{Abstract}

The anatomical structure of wood is in many branches of science and has been included in different sources in sections. In our country, only 5 books have been written in Turkish, describing the anatomical features of wood. Books; it has been written in the light of both translation and studies, and the terms it contains are taken directly from the existing biology terms or directly from the language into which it was translated, as it is read from the translated language or used in the form of creation by the author. In this study, different terms given to the concepts encountered in the existing sources were determined and attention was drawn to the confusion that occurred. With the determination of the terms that cause the current confusion, attention was drawn to this issue, and suggestions were made to make a joint decision with the relevant scientists on the use of the terms and to initiate the studies.

Keywords: Wood Anatomy, Term, Concept. 


\section{Giriş}

Türk Dil Kurumu (2011) sözlügüne göre terim; "Bir bilim, sanat, meslek daliyla veya bir konu ile ilgili özel ve belirli bir kavramı karşılayan kelime, 1stılah" şeklinde açıklanmıştır. Terimin kendine has özellikleri vardır. Bunlardan birisi, bildirdiği anlamın yoruma açık olmadığ1 ve kesinlik ifade ettiğidir. Anlamları sinırlı olan terimler, cümle içerisinde yanında bulunan bir kelimeye göre anlamca ve görevce değişiklik arz etmezler. Terim; mevcut bilimsel bir kavramın tek karşıllığ şeklinde olmalı, kavramları açık ve net şeklinde karşılamalı ve ilgili alana özgü olmalıdır (Zülfikar 1991).

Ülkemizde terim kullanımında Türkçe, Arapça, Farsça, Batı Dilleri etkili olmuş ve Cumhuriyetin ilan edilmesinden sonra Türkçe sözcüklerden yararlanılması kararlaştırılmış fakat bilimin ve teknolojinin hızla gelişmesine ayak uydurulamayarak Türkçe sözcükler tam anlamı ile kullanılamamıştır (Yumru, 2010).

Bilimsel terimler; aynı bilim dalıyla ilgili belirli kavramları açıklamak üzere özel olarak türetilmiş ve o bilim alanında çalışan insanların birbirleriyle iletişim kurabilmelerini sağlayan en önemli temel araçlardır. Terimler, eğitim ve öğretim etkinliği içinde kendine yer edinerek kuşaktan kuşağa geçmekte ve devamlılık sağlamaktadır. Ortak kelimelere dayanmayan bir bilim dili, kuşaklar arasinda kopukluk meydana getirebilmekte ve bilimsel anlamda dil aktarımı gerek eğitim ve öğretimde gerekse de toplumda düzgün bir şekilde gerçekleşememektedir. Bu nedenledir ki bir bilim dalında ortak terimlerin kullanımı çok önemlidir.

Bir kavramı karşılayan terimlerin, farklı şekillerde türetilmesi akademik çevrelerde ve ilgili alanın uzmanlarınca tartışılması ve ortak bir noktada buluşulması gerekirken birçok alanda var olan terim karmaşası farklı kitaplarda ve akademik makalelerde karşımıza çıkmaktadır. Sonuçta farklı kademelerde okutulan kitaplarda (ilköğretim, ortaöğretim ve yükseköğretim), dergilerde yayınlanan makalelerde aynı kavramlar için farklı terimler görülmektedir. Farklı dillerden yapılan çevirilerle ortaya çıkan kavramlara terim bulmak yerine ya o dilde doğrudan kullanılarak veya ait olduğu dilin Türkçe okunuşu ile terimler üretilmeye çalışılmaktadır.
Aynı kavramın farklı terimlerle anılması sonucunda ders kitapları arasında farklılık oluşmakta bu da öğrencilerin anlama güçlüğü yaşamasına neden olmaktadır. Terimlerdeki farklılı aynı zamanda bilimsel toplantılarda sunulan çalışmaların anlaşılması ve konu üzerinde tartısılması esnasında güçlükler yaşanmasına yol açmaktadır. Dergilere gönderilen makalelere yapılan hakemlik süreçlerinde kavramlara verilen farklı terimler bilim insanları arasında sorun teşkil etmektedir. Akademik yükseltmelerde yapılan yazılı ve sözlü sınavlarda ve çeşitli kurumlara sunulan bilimsel proje önerilerinde terimlerin ortak kullanılmaması olumsuz değerlendirmelere yol açabilmektedir.

Odun anatomisi, biyoloji bilim dalı içerisinde bitki anatomisi konusuna özel ve kendine özgü bir bilim dalıdır. Ülkemizde odun anatomisi konusu orman fakültelerinde orman endüstri mühendisliği bölümü lisans ve yüksek lisans, orman mühendisliği bölümü yüksek lisans/doktora ve bazı meslek yüksekokulları/yüksekokulları öğrencilerine çeşitli derslerde anlatılmaktadır. Ülkemizde "Odun Anatomisi” adında basılmış beş adet kitap bulunmaktadır. Bununla beraber odun anatomisi konusunu içeren ve yine bu konuyu içeren birçok ders kitabı ve akademik makaleler bulunmaktadır. Kitaplar ve akademik makaleler incelendiğinde bazı kavramların farklı farklı terimlerle anlatıldığı görülmüştür. Bu farklılıkların ortaya konması için bu çalışmada odun anatomisi ders kitaplarında detaylı bir inceleme yapılmış ve terim karmaşasına dikkat çekerek, konunun ilgili bilim insanları ile tartışılmasına ve bu karmaşanın giderilmesi için gereken çalışmaları teşvik etmek amaçlanmıştır.

\section{Materyal ve Yöntem}

Odunların anatomik yapısının anlatıldığ1 "Odun Anatomisi" ders kitaplarında (Bozkurt, 1992; Bozkurt ve Erdin, 1995; Bozkurt ve Erdin, 2000; Merev, 2003; Erdin ve Bozkurt, 2013) kullanılan terimler incelenmiş ve aynı kavramı işaret eden farklı terimler ele alınmıştır. Tüm kitaplar detaylı olarak incelenmiş, farklı olan terimler araşturılmıştır. Erdin ve Bozkurt (2013)'un yazmış olduğu kitap Bozkurt ve Erdin (2000)'un yazmış olduğu kitabın güncellenmiş ve genişletilmiş hali olduğu için tanımlar özellikle Erdin ve Bozkurt (2013)'un yazmış olduğu kitaptan alınmıştır.

Odunun yapısının ve teşhisinin anlatıldığı "Odun Anatomisi" kitaplarında farklı isimlerle tanımlanmış terimler belirlenmiş, bu terimlerin 
İngilizcesi, mevcut kullanımları, tanımları ve olas1 yazım farklılıkları tespit edilmiştir. Bu amaçla ilgili terimin sırası ile hangi konu başlı̆̆ altında bulunduğu, İngilizce karșillı̆̆, terimler ve terimlerin tanımlar1 ayr1 ayr1 sütunlarda olacak şekilde bir çizelgede birleştirilmiştir.

İnilizce terimleri tespit etmek amaciyla farklı ve yaygin kullanımı olan kaynaklar değerlendirmeye alınmıştır. Odun anatomisi konusunda uluslararası birliği sağlamak amacı ile kurulmuş olan Uluslararası Odun Anatomistleri Birliğine (International Association of Wood Anatomists- IAWA) ait sözlük ve teşhis anahtarları referans alınmıştır (IAWA 1964; 1989; 2004). Odunun makroskopik teşhisinde kullanılan bazı terimlerin İngilizcesi IAWA kaynaklarında bulunmamas1 nedeni ile "Wood Handbook" adlı kaynağın sözlügünden de faydalanılmıştır (FPL, 2010). Bu çalışmamızda terimlerin kökenleri konusuna değinilmemiştir.

\section{Bulgular ve Değerlendirme}

Ülkemizde mevcut Odun Anatomisi ismi ile basılmış kitaplar detaylı bir biçimde incelendikten sonra neticesinde 70 kavrama farkl terimlerin kullanıldığ1 tespit edilmiştir. Elde edilen bulgular Çizelge 1'de detaylı bir şekilde gösterilmiştir. İngilizce terimlerin hangi kaynaktan olduğu terimin yanına numara verilmek sureti ile belirtilmiş, açıklaması çizelge altında belirtilmiştir. Yine yapılan incelemelerde dikkati çeken diğer bir bulgu ise bir kavrama verilmiş terimin farklı kaynaklarda farklı şekilde yazılmış olmasıdır. Kaynaklarda mevcut yazım farklılığı olan 7 adet terim tespit edilmiştir.

Çizelgede de görüldüğü üzere terimler üç farklı şekilde ders kitaplarına girmiştir:

1-Yazarların oluşturduğu kelime grubu şeklinde kullanılan terimlerin çoğu yabancı dilden dilimize yapılan çeviri sonucu elde edilmiş terimlerdir. Örneğin; artım halkası, büyüme halkas1, yıllık halka, yaş halkası. Yine bir başka örnek; boyuna paranşim, odun paranşimi, aksiyal paranşim ve vertikal paranşim terimlerinin hepsi aynı kavramı tanımlamaktadır. Çevreye paralel bölünme (periklinal), periklinal bölünme ve boyuna teğet yönde bölünme üç farklı terim olmasına karşın aynı kavramı tarif etmektedir.

2-Birebir Türkçe karş1lığ1 bulunamayıp yabancı dildeki karşıllı̆ının olduğu gibi kullanıldığı terimler; örneğin; Trabeculae oluşumu, Crassulae oluşumu, Callitroid oluşumu, fusiform öz 1şını, margo, porus, terminal paranşim.

3-Çevirenin birebir Türkçe karşllı bulamayıp, Türkçe'de okunduğu şekli ile oluşturduğu terimler; örneğin; Trabekül (trabeculae) oluşumu, krasül (crassulae) oluşumu, sklerotik (sclerotic) tüller, jüvenil (juvenile) odun, skalariform (scalariform) perforasyon tablasi, traumatik (traumatic) reçine kanalı, druz (druse) kristeller, rafid (raphide), asikular (acicular) kristaller, mültiseri (mültiseriate) öz 1şını, inisiyal/inisyal (initial) sınır paranşimi, marjinal (marginal) paranşim vb. gibi.

Farklı yazarlar tarafindan çoğunlukla çeviri tarzında yazılmış olan kaynak kitaplarda terimlerin oluşturulmasında yukarıda belirtilen yöntemler kullanılmıştır. Bunların yanında yazarlar bazı terimlerin kullanımında karmaşa oluşturabileceğini düşündügünden terimin yanına parantez içerisinde İngilizce terimini, bazıları kendileri oluşturdukları Türkçe terimleri ve yine bazıları da eş anlamlı olabilecek terimleri eklemişlerdir. Bir kavramın başlı̆̆ına bakıldığında iki veya üç adet terimin gösterildiği görülmüştür. Örneğin Merev (2003) yalancı öz ışınları terimin yanına parantez içerisinde İngilizcesini yalancı öz ışını (aggregate rays) eklerken, Erdin ve Bozkurt (2013) ise yalanc ismini parantez içerisinde vererek bileşik (yalancı) öz 1şını terimini kullanmıştır. Bunun gibi birçok örnek yukarıda çizelgede verilmiştir. Bu şekilde ki yaklaşım bir kavramin birden fazla terimle anlatilmasina, böylelikle daha da karmaşıklaşmasına yol açmaktadır.

Karmaşaya yol açan diğer önemli bir nokta ise terimlerin yazılışından kaynaklanan sorunlardır. Terimde sadece bir harf farkllllğı ya da terimi oluşturan kelimelerin ayr1 ya da birleşik yazılması diğerlerinden farklı olmasina neden olmaktadır. Çizelge 2'de görüldüğü gibi her bir kitapta bazı terimler ufak harf farklılıkları ile kullanılmaktadır. Akademik çalısmaların yazım şeklinin kontrolü aşamasında bu şekilde karşılaşılan terimler değerlendirenin terminolojisine göre hatalı veya doğru olarak kabul edilebilmektedir. 
Çizelge 1. Odun anatomisi bilim alanına ilişkin terimler, İngilizcesi ve tanımları/terimin geçtiği cümle

\begin{tabular}{|c|c|c|c|}
\hline $\begin{array}{l}\text { Kullanılan terim } \\
\text { (-ler) }\end{array}$ & Konu & İngilizce & Tanım ve/veya terimin geçtiği cümle \\
\hline $\begin{array}{l}\text { Primer büyüme, } \\
\text { Primer büyüme (boy } \\
\text { artımı) }\end{array}$ & $\begin{array}{l}\text { Primer } \\
\text { büyüme }\end{array}$ & $\begin{array}{l}\text { Primer } \\
\text { growth [1] }\end{array}$ & $\begin{array}{l}\text { Odunsu bitkiler primer büyüme ile boy büyümesi yapmaktadır } \\
\text { (Merev 2003). } \\
\text { Primer büyüme (boy artımı) gövdede boyuna yöndeki } \\
\text { uzamalardır (Bozkurt, 1992; Erdin ve Bozkurt 2013) }\end{array}$ \\
\hline $\begin{array}{l}\text { Apikal meristem (primer } \\
\text { meristem, } \\
\text { prokambiyum), } \\
\text { Primer meristem } \\
\text { (promeristem), } \\
\text { Uç meristemler (apikal } \\
\text { meristem) }\end{array}$ & $\begin{array}{l}\text { Primer } \\
\text { büyüme }\end{array}$ & $\begin{array}{l}\text { Apical } \\
\text { meristem } \\
{[1]}\end{array}$ & $\begin{array}{l}\text { Boy büyümesini sağlayan doku "apikal” meristem (primer } \\
\text { meristem, prokambiyum)dur (Merev 2003). } \\
\text { Gövdede boyuna yönde uzamalar, dal ve köklerin uçlarındaki } \\
\text { tomurcuklarda bulunan primer meristem (promeristem) } \\
\text { tarafindan meydana getirilmektedir. Bu bölgeler, uç } \\
\text { meristemler (apikal meristem) veya büyüme noktaları olarak } \\
\text { bilinirler (Erdin ve Bozkurt 2013). }\end{array}$ \\
\hline Sekonder büyüme, & $\begin{array}{l}\text { Sekonder } \\
\text { Büyüme }\end{array}$ & $\begin{array}{l}\text { Secondary } \\
\text { growth }\end{array}$ & $\begin{array}{l}\text { Odunsu bitkiler sekonder büyüme ile çap artımı yapar (Merev } \\
\text { 2003). }\end{array}$ \\
\hline
\end{tabular}

(enine artım),

Sekonder büyüme (enine artım); odunsu bitkilerde çap

Sekonder büyüme (çap artımi)

yönünde olan artımdır (Bozkurt, 1992).

Odunsu bitkilerde çap ve çevre yönünde görülen artımdır (Erdin ve Bozkurt 2013).

Kambiyum (vasküler Kambiyum Cambium Kambiyum (Vasküler kambiyum) sekonder floemle sekonder

kambiyum), $\quad[1]$

1] ksilem arasında yer alan ve bulunduğu bitkide hayat boyu

Vaskular kambiyum bölünme özelliğini koruyan meristematik bir dokudur (Merev, 2003).

Kambiyum dış tarafa doğru sekonder floemi (iç kabuk), iç tarafa doğru ise sekonder ksilemi (odun) oluşturmaktadır (Bozkurt, 1992).

Çap ve çevredeki artışlar vaskular kambiyum adı verilen üreyimli bir tabaka tarafindan meydana getirilir (Erdin ve Bozkurt 2013).

İğimsi inisiyaller teğet yönde bölünerek yeni ksilem ve floem hücrelerini meydana getirirler. Buna periklinal bölünme denir (Bozkurt, 1992).

Çevreye paralel bölünme (periklinal), Periklinal bölünme, Boyuna teğet yönde bölünme $\begin{array}{ll}\text { Kambiyum } & \begin{array}{l}\text { Periclinal } \\ \text { division [1] }\end{array}\end{array}$ Kambiyum ana hücrelerinin radyal çeperleri, teğet çeperlerden daha kalındır. Bu özelliğin, kambiyum hücrelerinin çevreye paralel (periklinal) bölünmesinin bir sonucu olduğu söylenmektedir (Merev 2003).

İğimsi inisiyallerin gövde yüzeyine paralel, yani teğet bölünmesi periklinal bölünme olarak tanımlanır (Erdin ve Bozkurt 2013).

Yeni ksilem ve floem hücreleri kambiyum inisiyal hücrelerinin boyuna teğet yönde (periklinal) bölünmeleriyle oluşmaya başlarlar (Bozkurt, 1992; Erdin ve Bozkurt 2013).

Sekonder kalınlaşma sonucunda gövdenin çap1 arttığ1 için kambiyum tabakasının çap artımına uyum sağlaması bakımından, kambiyumun çevreye paralel yönde genişlemesi

Antiklinal veya lateral bölünme, Antiklinal bölünme

Kambiyum $\begin{aligned} & \text { Anticlinal } \\ & \text { devision [1] }\end{aligned}$
gerekir. Bu genişleme boyuna bölünmelerle (antiklinal veya lateral) yerine getirilir (Merev, 2003).

İğimsi inisiyaller radya yönde ya da pseudotransversal olarak bölünerek, kambiyumda çevre artımını sağlarlar. Bu tip bölünme şekli aktiklinal bölünme olarak tanımlanır (Erdin ve Bozkurt 2013).

Kambiyum iğimsi inisyalleri (fusiform inisyalleri); iğimsi
Kambiyum iğimsi inisyalleri (fusiform inisiyalleri), İğimsi inisiyaller
Cambial

$\begin{array}{ll}\text { Kambiyum } & \text { initial - } \\ & \text { Fusifom }\end{array}$ initial $[1,3]$ inisyaller odunda boyuna yöndeki uçları sivri elemanları oluşturur (lif, trahe, boyuna paranşim) (Merev, 2003).

İğimsi inisiyaller; iğne yapraklı ve geniş yapraklı ağaçlarda hem ksilem, hem de floemde bulunan ve boyuna yönde uzanan hücreleri meydana getiren ana hücrelerdir (Bozkurt, 1992; Erdin ve Bozkurt 2013). 
Çizelge 1'in devamı

\begin{tabular}{lll}
$\begin{array}{l}\text { Kullanılan terim } \\
\text { (-ler) }\end{array}$ & Konu & İngilizce \\
\hline $\begin{array}{l}\text { Kambiyum öz 1şını } \\
\text { inisyalleri, } \\
\text { Öz 1şını inisiyalleri }\end{array}$ & Kambiyum & $\begin{array}{l}\text { Cambial } \\
\text { initial -Ray } \\
\text { initial [1] }\end{array}$ \\
\end{tabular}

\section{Tanım ve/veya terimin geçtiği cümle}

Kambiyum öz 1şını inisyalleri; iğimsi inisyallerden daha küçük

olup, genellikle izodiyametrik hücrelerdir (Merev, 2003).
Öz 1şını inisiyalleri teğet kesitte çok sayıda gruplar halinde ve öz 1şını düzeninde bulunmaktadır (Bozkurt, 1992; Erdin ve Bozkurt 2013).

\begin{tabular}{|c|c|c|}
\hline $\begin{array}{l}\text { Sekonder ksilem, } \\
\text { Odun }\end{array}$ & Odun & $\begin{array}{l}\text { Xylem }[1,4] \\
\text { Secondary } \\
\text { xylem [1] }\end{array}$ \\
\hline
\end{tabular}

Kambiyum iç tarafa doğru sekonder ksilemi (odun) oluşturmaktadır (Bozkurt, 1992);

Kambiyum hücreleri gövdenin iç kısmına doğru da sekonder ksilemi yani “odunu” oluşturur (Merev, 2003).

Vaskular kambiyum oluşumundan sonra üretilen odun sekonder ksilem olarak tanımlanır (Erdin ve Bozkurt, 2013).

Hücre büyüklüklerinin yeknesak ya da değişik olması sonucu y1llık halkaların görünüşünde meydana gelen farklilıklara odunun tekstürü denir (Bozkurt, 1992).

Merev (2003) strüktür (Grain) terimini bir yıllık halka içerisinde yaz odunu zonunun, yıllık halkaya oranı odunun tekstürü

Tekstür, Strüktür (grain)

Odun

Texture [4], Grain [4] hakkında bilgi verir der iken strüktür terimini de yıllık halkayı oluşturan elemanların boyutları ile ilgili bir özellik olarak tanımlamıştır.

Odun dokusundaki hücre çeşitleri ve hücre büyüklüklerinin değişikliği ya da y1llık halkalar içerisinde ilkbahar-yaz odununun belirgin olarak birbirinden ayrilıp ayrilmaması sonucu meydana gelen farklılıklara odunun tekstürü denir (Erdin ve Bozkurt, 2013).

Ağaç gövdesinde öze yakın olan ve tacın başladığı yere kadar bir

\begin{tabular}{|c|c|c|}
\hline $\begin{array}{l}\text { Jüvenil odun, } \\
\text { Genç odun }\end{array}$ & Odun & $\begin{array}{l}\text { Juvenile } \\
\text { wood }[2,3]\end{array}$ \\
\hline
\end{tabular}
silindir oluşturan genç odun kısmıdır (Bozkurt, 1992).

Öz çevresine yakın olan oduna genç odun denir (Merev, 2003). Genellikle ağaçların ilk 2-20 (25) yılları arasında genç odun üretilmektedir (Erdin ve Bozkurt 2013).

Ksilemin fizyolojik bakımdan görevinin sona ermesiyle öz odun ad verilen bir tabaka teşekkül etmeye başlar (Bozkurt, 1992).

Pasif odun, Öz odun

Odun

Heartwood Su iletimini ve fizyolojik fonksiyonlar1 yerine getiremeyen ve paranşim hücreleri ölü olan özoduna pasif odun denir (Merev, $[1,2,3,4]$ 2003).

Birçok ağaç türünde gövde enine kesitinin yeknesak olmadığ 1 görülmekte, böyle gövdelerde özün etrafinda koyu renkli bir bölge ve dişa doğru açık renkli bir tabaka görünür. Ortadaki koyu renkli bölge öz odundur (Erdin ve Bozkurt 2013).

Dış kısımda yaşayan hücreler ihtiva eden ve ağaç türü ile ilgili olarak belli sayida yıllık halkadan ibaret bir diri odun tabakası bulunmaktadır (Bozkurt, 1992).

Aktif odun,

Diri odun
Odun Sapwood $[1,2,3,4]$
Su ileten elemanları aktif, paranşim hücreleri canlı ve tüm fizyolojik fonksiyonları yerine getiren özodunun çevresindeki diri oduna da aktif odun denir (Merev, 2003).

Birçok ağaç türünde gövde enine kesitinin yeknesak olmadığ1 görülmekte, böyle gövdelerde özün etrafinda koyu renkli bir bölge ve dışa doğru açık renkli bir tabaka görünür. Dış tarafta kalan açık renkli kısım diri odundur (Erdin ve Bozkurt 2013). 
Avrasya Terim Dergisi, 2021, 9 (2): 12 - 26

Çizelge 1'in devamı

\begin{tabular}{l}
$\begin{array}{l}\text { Kullanılan terim } \\
(- \text { ler })\end{array}$ \\
\hline
\end{tabular}

Islak odun (wet wood), Odun

Odun Wet wood $[2,3]$

\section{Tanım ve/veya terimin geçtiği cümle}

Islak öz odun

Islak odun genellikle kahverengi bir görünüm verir (Merev, 2003).

\section{İnce strüktürlü,}

İnce tekstür,

Yeknesak tekstür

Odun

Close-Grained

(Fine-Grained)

Wood [4],

Fine textured

[4]

Genellikle göknarlarda görülen ve olgun odundaki rutubet miktarının, normal rutubet miktarının 3 katı kadar artması ile ortaya çıkan "islak öz odunu" oluşumudur (Erdin ve Bozkurt 2013).

Koniferlerde traheitlerin çap1 ve özışını genişliği, dikotil odunlarda trahe teğet çapı ve özışını genişliği odunun strüktürü hakkında bilgi verir. Adı geçen elemanların boyutları küçüldükçe odun ince strüktürlü olarak kabul edilir (Merev, 2003).

Hücre çaplarının küçük olması ince tekstürü gösterir. Yeknesak tekstür belirgin olmayan öz 1şınları ile birlikte hücre lümen boyutlarında hem büyük farklılıklar olmaması hem de yıllık halka sınırının fazla belirgin olmaması ile tanımlanabilir (Erdin ve Bozkurt 2013).

Koniferlerde traheitlerin çap1 ve özışını genişliği, dikotil odunlarda trahe teğet çapı ve özışını genişliği odunun strüktürü

Kaba strüktürlü,

Kaba tekstür,

Yeknesak olmayan

Odun

Coarse-

Grained Wood

[4],

Open-grained

[4] hakkında bilgi verir. Adı geçen elemanların boyutları büyüdükçe odun kaba strüktürlü olarak kabul edilir (Merev, 2003).

Halkalı traheli ağaçlarda büyük trahelerin bir halka oluşturması veya veya büyük lümenli hücrelerin bulunması kaba tekstürü ifade etmektedir. Yeknesak olmayan (düzensiz) tekstüre ilkbahar-yaz odunu traheidlerinin kontrast olması örnek gösterilebilir (Erdin ve Bozkurt 2013).

Radyal kesit; öz 1şınlarına paralel boyuna yüzeydir (Bozkurt, 1992).

Radyal düzlem (quater sawn),

Radyal kesit,

Odun

Radial section

Kerestelerde radyal düzlem (quater sawn) bol miktardaki öz 1şını

Radyal yüzey

$[1,2,3]$

adacıklarından dolayı parlaktır (Merev, 2003).

Tomruklar öz işınlarına paralel ya da yıllık halkalara dik yönde boyuna olarak biçilirse; radyal yüzey ya da radyal kesit elde edilmektedir (Erdin ve Bozkurt 2013).

Teğet kesit; ağacın kabuğu soyulduğu zaman teğet yüzey ortaya ç1kmaktadır (Bozkurt, 1992).

Teğet düzlem (flat sawn),

Odun

Tangential

Teğet kesit section $[1,2,3]$

Kerestelerde radyal düzlem (quter sawn) bol miktardaki öz 1şını adacıklarından dolayı, teğet düzlemden (flat sawn) daha parlaktır (Merev, 2003).

Teğet kesit; y1llık halkalara teğet yönde biçilen ya da soyulan tomruklardan elde edilen ağaç malzemede yıllık halkalar köşeli, parabolik veya düzensiz konsantrik şekiller meydana getirirler (Erdin ve Bozkurt 2013).

Büyüme esnasinda vejetasyon mevsiminin, önce kurak sonra yağışlı geçmesi hallerinde ve özellikle yazları kurak geçen iklim mintıkalarında yalancı yıllık halkalara rastlanmaktadır (Bozkurt, 1992).

Çift yillık halka, Yalanc1 yıllık halka

Y1llik

halka
False annual ring [1] False growth ring [3]
Bir yıllık halka içinde birkaç yıllık halka sınırının bulunması halidir (Merev, 1998).

Mevsim içi değişiklikler ağacın uç kısımlarındaki meristematik büyümeyi durduğunda auxin hormonlarının üretimi azalmakta, yaz odunu tipinde hücreler oluşmaktadır. Bu olaylar boy büyümesini durdurmayıp yavaşlatırsa, tekrar uygun gelişme şartları oluştuğunda aynı yıl içerisinde ikinci kez ince çeperli ilkbahar odunu hücreleri üretilmektedir (Erdin ve Bozkurt 2013). 
Çizelge 1'in devamı

\begin{tabular}{|c|c|c|c|}
\hline $\begin{array}{l}\text { Kullanılan terim } \\
\text { (-ler) }\end{array}$ & Konu & İngilizce & Tanım ve/veya terimin geçtiği cümle \\
\hline $\begin{array}{l}\text { Devamsız y1llık halka, } \\
\text { Devamlı olmayan } \\
\text { y1llık halkalar }\end{array}$ & $\begin{array}{l}\text { Yillik } \\
\text { halka }\end{array}$ & $\begin{array}{l}\text { Discontinuous } \\
\text { ring [1], }\end{array}$ & $\begin{array}{l}\text { Devamlı olmayan yılllık halkalar; gövde enine kesitinde yıllık } \\
\text { halkaların tam bir halka teşkil edeceği yerde bazı kısımlarda yıllık } \\
\text { halkanın hiç teşekkül etmemesi halidir (Bozkurt, 1992). } \\
\text { Gövde enine kesitinde tam bir halka oluşmaması durumudur } \\
\text { (Merev, 2003). } \\
\text { Özün etrafinda tam bir halka oluşturmayan yılllk halkalardır } \\
\text { (Erdin ve Bozkurt, 2013). }\end{array}$ \\
\hline $\begin{array}{l}\text { Artım halkası, } \\
\text { Büyüme halkası, } \\
\text { Yıllık halka }\end{array}$ & Yillık halka & $\begin{array}{l}\text { Growth ring } \\
{[1,2,4] \text {, }} \\
\text { Annual ring } \\
{[1,4]}\end{array}$ & $\begin{array}{l}\text { Kambiyumun peryodik olarak bölünmesi yıllık halkaların } \\
\text { oluşmasını sağlar (Merev, 2003). } \\
\text { Ilıman iklim kuşağında yetişen ağaçlarda, gövde enine kesiti } \\
\text { incelendiğinde, özün etrafinda iç içe geçmiş halkalar şeklinde } \\
\text { görülen oluşumlara ylllık halka, artım halkası ya da büyüme halkası } \\
\text { denir (Erdin ve Bozkurt 2013). }\end{array}$ \\
\hline
\end{tabular}

$\begin{array}{lll}\text { Pektin lamel, } & & \text { Intercellular } \\ \text { Orta lamel } & \text { Hücre } & \text { layer, } \\ & \text { Çeper } & \text { Syn. Middle } \\ & \text { lamella [1] }\end{array}$

Doku içerisindeki hücreler primer çeperlerinin dışında kalan interselüler maddeyle birbirlerine bağlanmıştır. Amorf yapıdaki bu maddeye orta lamel veya pektinden yapıldığ için pektin lamel

denir (Merev, 2003).
İki bitişik hücrenin primer çeperleri arasında hücreleri birbirine bağlayan orta lamel bulunur ((Bozkurt, 1992); Erdin ve Bozkurt, 2013).

S3 tabakası bazen hücre lümenine doğru siğil tabası (warty layer)

\begin{tabular}{|c|c|c|c|}
\hline $\begin{array}{l}\text { Siğil tabakası, } \\
\text { Siğgilli tabaka }\end{array}$ & $\begin{array}{l}\text { Hücre } \\
\text { Çeper }\end{array}$ & $\begin{array}{l}\text { Warty layer } \\
{[3]}\end{array}$ & $\begin{array}{l}\text { denilen bir tabaka oluşturur (Merev, 2003). } \\
\text { Hücre çeperinin lümene bakan tarafinda oluşan, çıkıntılar } \\
\text { şeklindeki kalıntılar sitoplazmik karakterde olduğundan bu } \\
\text { tabakaya siğilli tabaka denir (Bozkurt, 1992; Erdin ve Bozkurt, } \\
\text { 2013). }\end{array}$ \\
\hline $\begin{array}{l}\text { Trabekül oluşumu, } \\
\text { Trabeculae oluşumu }\end{array}$ & Hücre & $\begin{array}{l}\text { Trabecula, } \\
\text { pl. } \\
\text { Trabeculae } \\
{[1]}\end{array}$ & $\begin{array}{l}\text { Bazı traheit hücrelerinin lümenlerini bölen bir yapıdır (Merev, } \\
\text { 2003). } \\
\text { Traheidlerde bir teğet çeperden diğgerine çubuk şeklinde uzanan } \\
\text { oluşumlardır (Bozkurt, 1992; Erdin ve Bozkurt 2013). }\end{array}$ \\
\hline $\begin{array}{l}\text { Krasül oluşumu, } \\
\text { Crassulae oluşumu, }\end{array}$ & $\begin{array}{l}\text { Hücre } \\
\text { çeperi }\end{array}$ & $\begin{array}{l}\text { Crassula(e) } \\
{[1]}\end{array}$ & $\begin{array}{l}\text { Traheidlerde radyal çeperler üzerinde geçitlerin alt ve üstünde } \\
\text { koyu renkli görünen kisımlara Crassulae adı veilmektedir } \\
\text { (Bozkurt, 1992). } \\
\text { Krasül oluşumu; kenarlı geçitler arasında, çeper kalınlaşması } \\
\text { sonucu ortaya çıkan oluşumdur (Merev, 2003). } \\
\text { Crassulae orta lamel ve primer çeperin yer yer kalınlaşması ile } \\
\text { meydana gelen oluşumbardır (Erdin ve Bozkurt 2013). }\end{array}$ \\
\hline $\begin{array}{l}\text { Helikal kalınlaşmalar, } \\
\text { Spiral kalınlaşmalar }\end{array}$ & $\begin{array}{l}\text { Hücre } \\
\text { çeperi }\end{array}$ & $\begin{array}{l}\text { Helical } \\
\text { thickenings } \\
{[2]} \\
\text { Spiral } \\
\text { thickenings } \\
{[1.2,3]}\end{array}$ & $\begin{array}{l}\text { Odun elemanlarındaki helikal veya spiral kalınlaşmalar hücre } \\
\text { çeper materyalinin hücre lümenine doğru yapmış olduğu } \\
\text { çıkntılardır (Merev, 2003). } \\
\text { Spiral kalınlaşmalar; bir çeşit kalınlaşma olup, mikrofibrillerden } \\
\text { oluşmuşlardır ve S3 tabakası üzerinde yer alırlar (Erdin ve Bozkurt } \\
\text { 2013). }\end{array}$ \\
\hline $\begin{array}{l}\text { Enine traheitler, } \\
\text { Öz ş̧ını traheidleri, } \\
\text { Enine traheidler }\end{array}$ & Hücre & $\begin{array}{l}\text { Ray tracheids } \\
{[1,3]}\end{array}$ & $\begin{array}{l}\text { Enine traheitler genellikle özışınlarının marjinal kısımlarında tek } \\
\text { veya çok sıra halinde çap yönünde uzun hücrelerdir. Enine } \\
\text { traheitler, çeperleri ligninleşmiş çap yönünde uzanan ölü } \\
\text { hücrelerdir (Merev, 2003). } \\
\text { Öz ışını traheidleri (enine traheidler) enine yönde uzanan ve radyal } \\
\text { yönde (yarıçap yönünde) besi suyu iletimini yapan hücrelerdir } \\
\text { (Erdin ve Bozkurt 2013). }\end{array}$ \\
\hline
\end{tabular}
denilen bir tabaka oluşturur (Merev, 2003). 
Çizelge 1'in devamı

Kullanılan terim Konu İngilizce Tanım ve/veya terimin geçtiği cümle
(-ler)

Combretaceae, Lythraceae, Myrtaceae, Rubiaceae familyası türleri ile Leguminosae familyasının birçok türünde geçit odası ve porusların tamamen veya kısmen püskül şseklinde oluşumlarla doldurulmuştur. Bu geçitlere püsküllü geçitler adı verilmektedir

Örtülü intervasküler geçitler (Vestured/

Vesturing),

Örtülü geçitler,

(Vesturing),

Püsküllü geçit,

Geçit örtüleri,

Örtü oluşumu
(Bozkurt ve Erdin, 1995).

Örtülü intervasküler geçitler (vestured/vesturing): İntervasküler geçitlerin apertürlerini ve geçit odasını tümüyle veya kısmen örten sekonder çeper çıkıntılarıdır. Başka bir ifade de ise geçit örtüleri;

Vestured pit $[1,2]$ trahe, vasisentrik/vasküler traheit ve traheit liflerinin kenarlı geçitlerinin geçit odası ve apertürlerinde dişa doğru oluşan uzantılarıdır şeklinde tanımlanmıştır. Kaynak içerisinde başka bir konu içerisinde de siğilli tabaka ile Angiospermae odunu elemanlarının kenarlı geçitlerindeki örtü oluşumu (vestured) aynı oluşumlar değildir diye bir ifade bulunmaktadır (Merev, 2003).

Angiosperm'lerde siğilli yapıyı basit veya kenarlı geçitlerde dallanmış oluşumlar ile birlikte görmek mümkün olmakta ve bunlar püsküllü geçitler olarak tanımlanmaktadır (Erdin ve Bozkurt 2013).

\begin{tabular}{|c|c|c|c|}
\hline $\begin{array}{l}\text { Porus, } \\
\text { Geçit açıklı̆̆1, } \\
\text { Apertür, } \\
\text { Geçit ağz1 }\end{array}$ & Geçit & $\begin{array}{l}\text { Pit aperture } \\
{[1,2,3]}\end{array}$ & $\begin{array}{l}\text { Ortada geçit ağzı (porus) adı verilen bir boşluk vardır (Bozkurt, } \\
\text { 1992). } \\
\text { Geçitin iki hücre lümenine bakan açıklığına porus veya geçit açıklığı } \\
\text { (apertür) denir (Merev, 2003). Geçitlerin ortasında geçit ağzı (porus) } \\
\text { olarak tanımlanan bir boşluk vardır (Erdin ve Bozkurt 2013). }\end{array}$ \\
\hline $\begin{array}{l}\text { Geçit zar1, } \\
\text { Margo } \\
\text { Geçit membranı, }\end{array}$ & Geçit & $\begin{array}{l}\text { Pit } \\
\text { membrane } \\
{[1,3]} \\
\text { Margo [3], } \\
\text { Scalloped } \\
\text { torus [1] }\end{array}$ & $\begin{array}{l}\text { Diri odunda geçit zarı (margo) kısmında mevcut olan açıklıklar } \\
\text { yardımıyla iğne yapraklı ağaçlarda traheidden traheide sıvı iletimi } \\
\text { mümkün olmaktadır (Bozkurt, 1992). } \\
\text { Torusu geçit kenarına bağlayan kısma margo (geçit zarı veya geçit } \\
\text { membranı) denir (Merev, 2003). } \\
\text { Torus ile geçit kenarı arasında kalan geçit zarı kısmına margo denir } \\
\text { (Erdin ve Bozkurt 2013). }\end{array}$ \\
\hline $\begin{array}{l}\text { Loblu torus, } \\
\text { Dişli torus }\end{array}$ & Geçit & $\begin{array}{l}\text { Pits with } \\
\text { notched } \\
\text { borders [3] }\end{array}$ & $\begin{array}{l}\text { Loblu torus; torusun çevresinin loblu veya dişli olmasıdır (Merev, } \\
\text { 2003). } \\
\text { Dişli torus; torusun kenarlarının dişli yapıda olmasıdır (Erdin ve } \\
\text { Bozkurt 2013). }\end{array}$ \\
\hline $\begin{array}{l}\text { Callitroid kalınlaşma, } \\
\text { Callitrisoid tip } \\
\text { kalınlaşma }\end{array}$ & Geçit & $\begin{array}{l}\text { Callitroid } \\
\text { thickenings } \\
\text { Syn: } \\
\text { Callitrisoid } \\
\text { thickenings } \\
\text { [3] }\end{array}$ & $\begin{array}{l}\text { Callitroid kalınlaşma; kenarlı geçitlerde porusun altında ve üstünde, } \\
\text { enine yönde uzanan bir çift kalınlaşma şeklinde görülür (Bozkurt ve } \\
\text { Erdin, 1995). } \\
\text { Callitrisoid tip kalınlaşma; bazı odunlarda, porusun iki ucunda yer } \\
\text { alan boynuz şeklinde çıkıntılara denir (Merev, 2003). } \\
\text { Callitroid kalınlaşma; teğet kesitte porusun üzerinde boynuz } \\
\text { şeklinde ç1kıntılar, radyal kesitte yine porusun alt ve üstündeki koyu } \\
\text { renkli uzantılar olarak görülmektedir (Bozkurt, 1992; Erdin ve } \\
\text { Bozkurt 2013). }\end{array}$ \\
\hline $\begin{array}{l}\text { Düğümlü } \\
\text { kalınlaşmalar, } \\
\text { Uç çeperler düğümlü, } \\
\text { Nodüler kalınlaşma, } \\
\text { Nodül oluşumu }\end{array}$ & Hücre & $\begin{array}{l}\text { Nodular } \\
\text { end Wall } \\
{[1,3]}\end{array}$ & $\begin{array}{l}\text { Boyuna paranşimlerin enine yöndeki uç çeperlerinde basit geçitler } \\
\text { vardır. Bunlar boyuna kesitte düğümlü kalınlaşmalar şeklinde } \\
\text { görülürler (Bozkurt, 1992). } \\
\text { Bazı türlerde boyuna paranşim hücrelerinin uç çeperlerinde düğüm } \\
\text { şeklinde kalınlaşmalar görülmektedir (Bozkurt ve Erdin, 1995). } \\
\text { Boyuna paranşimlerin enine çeperlerindeki nodül oluşumu türlere } \\
\text { has özelliktir (Merev, 2003). } \\
\text { Bazı türlerde uç uca sıralanmış öz ışını paranşim hücreleri arasında } \\
\text { iletimi sağlayan geçitlerin yakınında önemli derecede çeper } \\
\text { kalınlaşması, dügümlü kalınlaşmalar (nodüler kalınlaşma) } \\
\text { görülmektedir (Erdin ve Bozkurt 2013). }\end{array}$ \\
\hline
\end{tabular}


Çizelge 1'in devamı

\section{Kullanılan terim (-ler)}

Pencere tipi geçitler, Pencere şeklinde geçitler

\begin{tabular}{|c|c|c|}
\hline $\begin{array}{l}\text { İğimsi öz 1şını, } \\
\text { Fusiform öz1ş1n1 }\end{array}$ & Hücre & $\begin{array}{l}\text { Fusiform } \\
\text { ray }[1,3], \\
\text { Syn. } \\
\text { Lenticular } \\
\text { ray [1] }\end{array}$ \\
\hline $\begin{array}{l}\text { Traumatik reçine } \\
\text { kanalı, } \\
\text { Patolojik (traumatik) } \\
\text { reçine kanalı }\end{array}$ & Hücre & $\begin{array}{l}\text { Traumatic } \\
\text { resin canals } \\
{[3],} \\
\text { Intercellula } \\
\text { r traumatic } \\
\text { canal [1] }\end{array}$ \\
\hline $\begin{array}{l}\text { Halkalı traheliler, } \\
\text { Halkalı traheli odunlar }\end{array}$ & $\begin{array}{l}\text { Trahe } \\
\text { düzeni }\end{array}$ & $\begin{array}{l}\text { Ring- } \\
\text { porous } \\
\text { wood }[1,2]\end{array}$ \\
\hline
\end{tabular}

Yarı halkalı traheliler, Yar1-halkalı traheli odunlar

Trahe düzeni
Wood semi-ringporous $[1,2]$

\section{İngilizce Tanım ve/veya terimin geçtiği cümle}

Window- 2003).

Pencere şeklinde çoğunlukla büyük boyutlu basit geçitlerdir (Merev, Karsitasm çamlarda görülen büyük geçitlerdir (Erdin ve Bozkurt 2013).

İğimsi öz ışınlarında, hem öz ışını paranşimleri ve öz ışını traheidleri hem de reçine kanalları çevresinde epitel hücrelerini ihtiva etmektedirler (Bozkurt, 1992);

Enine reçine kanallı özışınlarına fusiform özışını denir (Merev, 2003).

İğimsi öz 1şınları içerisinde reçine kanalı bulunmakta ve kanalın çevresinde öz 1şını dişarıya doğru çıkıntı yapmaktadır. Bu öz 1şınlarının teğet kesitteki görüntüsü bir iğ şeklinde olduğundan, "iğimsi” ya da "fusiform" öz ışınları olarak tanımlanırlar (Erdin ve Bozkurt, 2013).

Traumatik reçine kanalları yaralanma ile meydana gelen reçine kanallarıdır (Bozkurt, 1992).

Patolojik (traumatik) reçine kanalları odunun darbe gördüğü bölgelerde, yara kapatma ve bitkiyi diş etkilerden koruma amaçlı olarak meydana gelirler (Merev, 2003).

Don, yangin ya da mekanik etkiler ile yaralanma sonucu meydana gelen kanallardır (Erdin ve Bozkurt, 2013).

Halkalı traheli, ilkbahar odunu trahelerinin aynı yıllık halka içindeki veya bir önceki yıllık halkanın yaz odunundaki trahelerden belirgin bir şekilde daha büyük olması halindeki özelliktir (Bozkurt ve Erdin, 1995).

Halkalı traheli odunlarda ilkbahar odunu traheleri, yaz odunu trahelerine oranla çok büyük çaplıdır ve enine kesitte genellikle çıplak gözle görülebilir (Merev, 2003).

İlkbahar odunlarındaki traheleri, yaz odunundakilerden çok büyük ağaçlar "halkalı traheli" olarak tanımlanmaktadır (Bozkurt, 1992; Erdin ve Bozkurt, 2013).

Yarı halkalı traheliler; ilkbahar odunundaki traheler bir önceki yıllık halkanın yaz odunundakinden belirgin şekilde daha büyüktür. Ancak aynı yıllık halkanın ilkbahar odunundan, yaz odununa doğru bulunan traheler ile yaz odunu traheleri yavaş yavaş değişmekte ve giderek daha küçük traheler görülmektedir (Bozkurt ve Erdin, 1995).

Yarı halkalı traheli odunlarda, traheler yıllık halka içinde halkalı ve dağınık traheli arası yapıdadır (Merve, 2003).

İkbahar odunu traheleri ile yaz odunu traheleri arasındaki çap farkı fazla değilse ve trahe çapları yıllık halka sınırına doğru yavaş yavaş bir azalma gösteriyorsa, bu gruba giren ağaçlar " yarı halkalı" traheliler olarak adlandırılmaktadır (Erdin ve Bozkurt, 2013).

Dağınık traheli; trahelerin yıllık halka boyunca az çok aynı çaplarda bulunması halinde bu tip trahe düzeni söz konusu olmaktadır
Dağınık traheliler,

Dağınık traheli odunlar,
Trahe düzeni
Wood

diffuseporous $[1,2]$
(Bozkurt ve Erdin, 1995).
Dağınık traheli odunlarda, ilkbahar ve yaz odunu trahelerinin çapları arasinda belirgin bir fark yoktur (Merev, 2003).

Traheler yeknesak büyüklükte ve yıllık halka içerisinde düzenli bir dağılışta iseler, bu gruba giren ağaçlar "dağınık traheliler" olarak tanımlanır (Erdin ve Bozkurt, 2013). 
Çizelge 1'in devamı

Kullanılan terim Konu Ingilizce Tanım ve/veya terimin geçtiği cümle
(-ler)

Merdivenimsi

perforasyon tablas1, Skalariform

Hücre perforasyon tablas 1
Scalariform perforation plate $[1,2]$

Merdivenimsi perforasyon tablası; birden fazla birbirine paralel bölmeli, dallanmamış perforasyon tablası tipidir (Bozkurt ve Erdin, 1995)

Skalariform perforasyon tablasi: perforasyon tablas1 merdiven şeklindedir (Merev, 2003).

İki trahe arasında çok sayıda birbirine paralel açıklıklar şeklinde bir boşluk oluşumu bulunuyorsa merdivenimsi perforasyon tablası olarak tanımlanmaktadır (Bozkurt, 1992; Erdin ve Bozkurt, 2013).

Çok delikli perforasyon tablası: bir elekte olduğu gibi yuvarlak ya da

Çok delikli

perforasyon tablas1,

Retiküle perforasyon tablası
Hücre

Reticulate perforation plates $[1,2]$ eliptik açıklıklara sahip perforasyon tablası tipidir (Bozkurt ve Erdin, 1995).

Retiküle perforasyon tablası: trahe hücrelerinin enine çeperleri ăg şeklinde erir ve çok delikli bir görünüş arz eder (Merev, 2003).

Egzotik ağaçların bazılarında çok delikli perforasyon tablalarına rastlanmaktadir (Erdin ve Bozkurt, 2013).

Traheler arası geçitler merdivenimsi,

Merdivenimsi tipteki geçitler,

Geçit

geçitler,

Merdiven şeklinde

geçitler (scalariform)
Skalariform tip kenarlı

Traheler arası geçitler merdivenimsi; traheler arası geçitlerin merdiven basamakları şeklinde uzaması ile oluşan geçit tipleridir (Bozkurt ve Erdin, 1995).

Scalariform Skalariform tip kenarlı geçitler, trahe hücrelerinin çeperleri üzerinde pitting [1], horizontal yönde uzun, trahe hücresinin genişliğini kapsayacak Scalariform şekilde merdiven basamakları gibi sıralanmıstır. Aynı kaynakta geçit intervessel tipleri sınıflandırılırken merdiven şeklinde geçit (scalariform) terimi pits [2] de kullanılmışıtır (Merev, 2003).

Merdivenimsi tipteki geçitler; trahe eksenine dik yönde ve üst üste dizilerek bir merdiveni andiran geçitlerdir (Erdin ve Bozkurt, 2013). Almaşlı olanlar az sayıda ise yuvarlak veya oval biçimdedir (Bozkurt, 1992).

Almaşlı (diagonal),

Traheler arası geçitler

diagonal sıralı,

Almaçlı geçitler

(diagonal),

Geçit

Almaçlı geçit

(alternate),

Almaçlı dizilmiş

kenarlı geçit,

\begin{tabular}{l}
\hline Traheler arası geçitler \\
karşılıklı, \\
Karşılıklı (yatık sıralı) \\
dizilişteki geçitler, \\
Karşılıklı geçit \\
(opposite),
\end{tabular}

Alternate pitting

$[1,3]$, Alternate intervessel pits [2]
Traheler arası geçitler diagonal sıralı; traheler arası geçitler diagonal sıralar halinde dizilmiştir (Bozkurt ve Erdin, 1995).

Çeper üzerine almaçlı dizilmiş kenarlı geçitler daire şeklinde veya oval olabilir. Aynı kaynakta geçit tipleri sınıflandırılırken almaçlı geçit (alternate) terimi de kullanılmıştır (Merev, 2003).

Almaçlı geçitler (diagonal); trahe-trahe arasında bulunan, yuvarlak ve oval biçimde çoğunlukla altı köşeli (hekzagonal) geçitlerdir (Erdin ve Bozkurt, 2013).

Traheler arası geçitler karşılıklı; traheler arası geçitler kısa ile uzun
Opposite pitting [3], Karşllıklı geçitler (opposite); kısa veya uzun horizontal seriler Geçit Opposite intervessel Karşılıklı (yatık sıralı) dizilişteki geçitler horizontal sıralar halinde ve pits [2] halinde çeperi kaplarlar (Merev, 2003).

dikdörtgen ya da oval şeklindedir (Erdin ve Bozkurt, 2013).
Tüller; trahe bitişiğinde bulunan bir öz ışını ya da boyuna paranşim hücresinin trahe çeperindeki bir geçitten lümene doğru genişleyerek kısmen veya tamamen trahe lümenini doldurması halidir (Bozkurt ve Erdin, 1995). $\begin{array}{ll}\text { Tylosis, } & \text { Tiller, trahelere komşu boyuna ve özışın paranşim hücre } \\ & \text { içeriklerinin ortak geçitler vasitası ile trahe lümenine girip, lümeni }\end{array}$ Tül, Til Hücre Tylosis, pl. Thloses $[1,2]$ doldurması ile oluşur (Merev, 2003).

Tüller; bir trahenin bitişiğinde bulunan paranşim hücrelerinin protoplazması, koruyucu tabaka ile birlikte baloncuk gibi genişleyip geçitlerden geçerek, torba şeklindeki trahe lümenini tamamen veya kismen doldurmasi ile meydana gelmektedir (Erdin ve Bozkurt, 2013). 
Çizelge 1'in devamı

\begin{tabular}{l}
$\begin{array}{l}\text { Kullanılan terim Konu İngilizce } \\
\text { (-ler) }\end{array}$ \\
\hline
\end{tabular}

\begin{tabular}{|c|c|c|}
\hline $\begin{array}{l}\text { Sklerotik tüller, } \\
\text { Kristalli tiller }\end{array}$ & Hücre & $\begin{array}{l}\text { Sclerotic } \\
\text { tyloses [1,2] }\end{array}$ \\
\hline $\begin{array}{l}\text { Yapraklı ağaç } \\
\text { traheidleri, } \\
\text { Geniş yapraklı ağaç } \\
\text { traheidleri, } \\
\text { Yedek iletim } \\
\text { elemanları }\end{array}$ & Hücre & $\begin{array}{l}\text { Tracheids } \\
{[1,2] \text {, }} \\
\text { Tracheary } \\
\text { elements [1] }\end{array}$ \\
\hline
\end{tabular}

Tillerin arasına, bazı türlerde kristaller yerleşebilir. Böyle tillere

$\begin{array}{llll}\begin{array}{l}\text { Sklerotik tüller, } \\ \text { Kristalli tiller }\end{array} & \text { Hücre } & \begin{array}{l}\text { Sclerotic } \\ \text { tyloses [1,2] }\end{array} & \begin{array}{l}\text { kristalli tiller denir (Merev, 2003) } \\ \text { Tüllerin lümenlerinde koyu renkli maddeler ve kristaller } \\ \text { bulunabilir, bu tip tüller "sklerotik tüller" olarak tanımlanmaktadır }\end{array}\end{array}$ (Erdin ve Bozkurt, 2013).

Yapraklı ağaç traheidleri iki çeşittir (Bozkurt, 1992); Su iletimini üstlenen hücrelere yedek iletim elemanları denmektedir (Merev, 2003).

Geniş yapraklı ağaçların bazılarında vaskular traheidler ve vasisentrik traheidler olmak üzere iki tip traheid görülmektedir (Erdin ve Bozkurt, 2013).

Uçları kapalı hücreler olup, büyüklük, şekil, geçit yapısı ve çeperleri bakımından küçük çaplı trahelere benzemektedirler (Bozkurt ve Erdin, 1995).

Vaskular traheid

Vasküler traheit

Hücre Vascula

Ağaç boyu yönünde muntazam, ligninleşmiş çeperleri ile ölü tracheids hücrelerdir (Merev, 2003).

$[1,2] \quad$ Bulundukları yer, boyutları, şekilleri, geçitleri, çeper yapısı ve bulundukları yer itibariyle yaz odunu trahelerine çok benzerler, uçları kapalı ve perforasyon tablaları bulunmayan hücrelerdir (Erdin ve Bozkurt, 2013).

Lif traheidleri, Traheit lifleri

Hücre

Fibre-

tracheids

$[1,2]$ Traheit lifleri ağaç boyu yönünde ince, uzun, uçları sivri ve

ligninleşmiş sekonder çeperli ölü hücrelerdir (Merev, 2003).
Lif traheidleri belirgin olarak kenarlı geçitlere sahip ve por uzun, yarık şeklinde olan hücrelerdir (Erdin ve Bozkurt, 2013). Boyuna paranşim (aksiyal, longitudinal ve vertikal veya odun

Boyuna paranşim, Odun paranşimi, Aksiyal paranşim,

Vertikal paranşim,

Hücre

Axial

düzeni parenchyma

$[1,2,3]$ paranşimi) kambiyumun fusiform inisyallerinden meydana gelen ağaç boyu yönünde uzun hücrelerdir (Merev, 2003).

(1)

hich

hücreler seklinde görülen, k1sa, sadece basit geçitleri bulunan hücrelerdir. $\mathrm{Bu}$ hücrelere "odun paranşimi” olarak da tanımlanmaktadır (Erdin ve Bozkurt, 2013).

Apotraheal boyuna paranşimler teğet sıralı; paranşim strendlerinin teğet ya da eğik sıralı gruplar halinde bulunması şeklidir (Bozkurt

Apotraheal teğet sıralı, Apotraheal-kesik

Hücre zincir şeklinde düzeni paranşim

Apotracheal axial parenchyma diffuse-inaggregates [2] ve Erdin, 1995).

Apotraheal-kesik zincir şeklinde paranşim (apotracheal diffusein-aggregates); paranşim zincirleri yıllık halka içinde teğet yönde 2-4 hücre uzunluğunda liflerin arasında homojen bir şekilde dağılmıştır (Merev, 2003).

Apotraheal teğet sırali; paranşim hücreleri kısa teğet sıralar halinde bulunur (Erdin ve Bozkurt, 2013).

\begin{tabular}{|c|c|c|c|}
\hline $\begin{array}{l}\text { Boyuna paranşimler } \\
\text { kümeli, } \\
\text { Paratraheal kümeli, } \\
\text { Paratraheal-dağınık } \\
\text { (scanty paratracheal) }\end{array}$ & $\begin{array}{l}\text { Hücre } \\
\text { düzeni }\end{array}$ & $\begin{array}{l}\text { Scanty } \\
\text { paratracheal } \\
\text { parenchyma } \\
{[1],} \\
\text { Axial } \\
\text { parenchyma } \\
\text { scanty } \\
\text { paratracheal } \\
{[2]}\end{array}$ & $\begin{array}{l}\text { Boyun paranşimler kümeli; boyuna paranşim hücrelerinin traheler } \\
\text { etrafinda yer yer kümeler halinde birlikte bulunması ya da } \\
\text { tamamlanmayan bir halka oluşturması halidir (Bozkurt ve Erdin, } \\
\text { 1995). } \\
\text { Paratraheal-dağınık (scanty paratracheal); trahelerin çevresinde } \\
\text { birkaç adettir (Merev, 2003). } \\
\text { Paratraheal kümeli; tek tek veya gruplar halinde trahelerin } \\
\text { çevresinde bulunurlar (Erdin ve Bozkurt, 2013). }\end{array}$ \\
\hline
\end{tabular}


Çizelge 1'in devamı

\begin{tabular}{|c|c|c|}
\hline $\begin{array}{l}\text { Kullanılan terim } \\
\text { (-ler) }\end{array}$ & Konu & İngilizce \\
\hline $\begin{array}{l}\text { Boyuna paranşimler } \\
\text { halkall, } \\
\text { Paratraheal halkall, } \\
\text { Paratraheal- } \\
\text { vasisentrik } \\
\text { (Vasicentric) }\end{array}$ & $\begin{array}{l}\text { Hücre } \\
\text { düzeni }\end{array}$ & $\begin{array}{l}\text { Vasicentric } \\
\text { parenchyma [1], } \\
\text { Paratracheal axial } \\
\text { parenchyma } \\
\text { vasicentric [2] }\end{array}$ \\
\hline
\end{tabular}

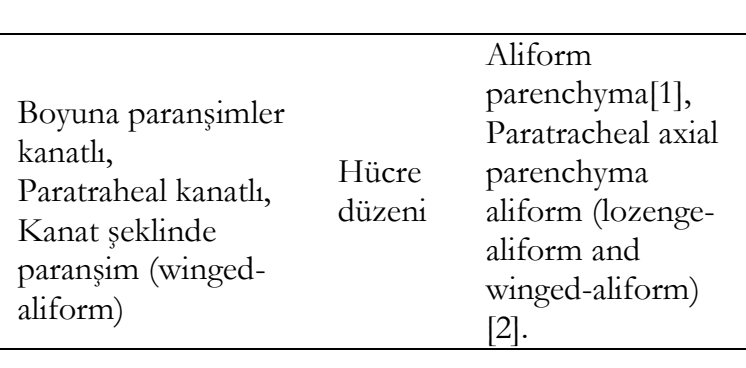

Boyuna paranşimler bileşik kanatli, Paratraheal bileșik kanatli, Birleşmiş kanat şeklinde paranşim (confluent)

\section{Tanım ve/veya terimin geçtiği cümle}

Boyuna paranşimler halkalı; boyuna paranşim hücrelerinin bir veya birkaç trahe etrafinda yuvarlak ya da oval, tam bir halka oluşturmasıdır (Bozkurt ve Erdin, 1995).

Paratraheal-vasisentrik (Vasicentric); trahenin veya trahe gruplarının çevresini tabaka halinde sarar (Merev, 2003).

Paratraheal halkalı; trahelerin çevresinde bir veya birkaç sıra hücreden meydana gelen bir halka oluştururlar (Erdin ve Bozkurt, 2013).

Boyuna paranşimler kanatlı; Traheleri çevreleyen boyuna paranşimler tek ya da çift taraflı, yanlarda uzantılar şeklinde ise bu özellik geçerlidir (Bozkurt ve Erdin, 1995).

Kanat şeklinde paranşim (winged-aliform) trahelerin etrafinı saran paranşim hücreleri lateral yönde uzantılar oluşturur (Merev; 2003). Paratraheal kanatli; trahelerin etrafinı sararak yanlarda kanat gibi çıkıntılar oluştururlar (Erdin ve Bozkurt, 2013).

Boyuna paranşimler bileşik kanatli; iki ya da daha fazla traheyi, halka ya da kanatlı şekilde çevreleyen boyuna paranşimlerin birleşerek sık sık düzensiz şeritler oluşturması halinde geçerli olan özelliktir (Bozkurt ve Erdin, 1995).

Paratraheal bileşik kanatli; birleşmiş kanat şeklinde paranşim (confluent); trahelerin çevresindeki vasisentrik veya kanat şeklindeki paranşimler, lateral yöne kollar uzatarak aynı şekilde traheleri saran paranşimle birleşerek birkaç traheyi lateral yönde birbirine bağlar (Merev, 2003).

Paratraheal bileşik kanatli; kanatlı boyuna paranşimlerin birleşmesi ile meydana gelmiş paratraheal dağılış tipi olup, teğet ya da diagonal bir düzen gösterirler (Erdin ve Bozkurt, 2013).

Boyuna paranşimler tek yanli; trahelerin sadece bir tarafinda şapka şeklinde, teğet ya da meyilli olarak uzamış bileşik kanatlı ya da

Boyuna paranşimler tek yanl,

Paratraheal tek yanlı paranşimler, Ünilateral paranşim (unilateral paratracheal)
Unilaterally paratracheal parenchyma [1],

Hücre Paratracheal axial düzeni parenchyma unilateral paratracheal [2] şeritli düzende olan paratraheal boyuna paranşimler bu özellik altında toplanmaktadır (Bozkurt ve Erdin, 1995).

Ünilateral paranşim (unilateral paratracheal); paranşim hücreleri trahelerin sadece üst kısmını sarar. Lateral yönde uzantıları da bulunabilir (Merev, 2003).

Paratraheal tek yanlı paranşimler; boyuna paranşimler traheyi tek yanlı olarak çeşitli şekillerde çevreleyebilir (Erdin ve Bozkurt, 2013)

Yıllık halka sınırında değişik genişlikte, az çok devamlı bir tabaka oluşturan paranşim şeritlerine, sınır paranşimi adı verilmektedir (Bozkurt ve Erdin, 1995).

$\begin{array}{lll}\text { Marjinal paranşim, } & \text { Hücre } & \text { Marginal } \\ \text { Sınır paranşimi } & \text { düzeni } & \text { parenchyma [2] }\end{array}$
Marjinal paranşim; yıllık halka sınırında değişik kalınlıkta, teğet yönde devamlı veya kesintili paranşim bantlarıdır (Merev, 2003). Sınır paranşimi; boyuna paranşim hücreleri yıllık halkaların başında ya da sonunda, tek veya birkaç sıra halinde bulunurlar (Erdin ve Bozkurt, 2013).

\begin{tabular}{|c|c|c|c|}
\hline $\begin{array}{l}\text { İnisiyal sınır } \\
\text { paranşimi, Marjinal- } \\
\text { inisyal }\end{array}$ & $\begin{array}{l}\text { Hücre } \\
\text { düzeni }\end{array}$ & $\begin{array}{l}\text { Initial } \\
\text { parenchyma [2] }\end{array}$ & $\begin{array}{l}\text { Marjinal paranşim yıllık halkaların ilkbahar odunu (marjinal- } \\
\text { inisyal) sınırında oluşur (Merev, 2003). } \\
\text { Yıllık halkaların başında bulunan sınır paranşimlerine inisiyal sınır } \\
\text { paranşimi denir (Erdin ve Bozkurt, 2013). }\end{array}$ \\
\hline $\begin{array}{l}\text { Marjinal-terminal, } \\
\text { Terminal sinır } \\
\text { paranşimi, }\end{array}$ & $\begin{array}{l}\text { Hücre } \\
\text { düzeni }\end{array}$ & $\begin{array}{l}\text { Terminal } \\
\text { parenchyma [2] }\end{array}$ & $\begin{array}{l}\text { Marjinal paranşim yıllık halkaların yaz odunu (marjinal-terminal) } \\
\text { sınırında oluşur (Merev, 2003). } \\
\text { Yıllık halkaların son kısmında bulunan sinır paranşimlerine } \\
\text { terminal sinır paranşimi denir (Erdin ve Bozkurt, 2013). }\end{array}$ \\
\hline
\end{tabular}


Çizelge 1'in devamı

\begin{tabular}{lll}
$\begin{array}{l}\text { Kullanılan terim } \\
\text { (-ler) }\end{array}$ & $\begin{array}{l}\text { Kon } \\
\mathbf{u}\end{array}$ & İngilizce \\
\hline $\begin{array}{l}\text { Homoselüler özışını, } \\
\begin{array}{l}\text { Homojen } \\
\text { (homoselüler) öz ışını }\end{array}\end{array}$ & Hücre & $\begin{array}{l}\text { Homogeneous } \\
\text { ray [1] }\end{array}$ \\
\hline
\end{tabular}

\begin{tabular}{|c|c|c|}
\hline $\begin{array}{l}\text { Heteroselüler özışını, } \\
\text { Heterojen } \\
\text { (heteroselüler) öz 1şını }\end{array}$ & Hücre & $\begin{array}{l}\text { Heterogeneous } \\
\text { ray [1] }\end{array}$ \\
\hline $\begin{array}{l}\text { Tek sıralı öz 1şını, } \\
\text { Üniseri özışını }\end{array}$ & Hücre & $\begin{array}{l}\text { Uniseriate rays } \\
{[1,2]}\end{array}$ \\
\hline
\end{tabular}

Çok sıralı öz ışını,
Mültiseri özışını $\quad$ Hücre $\begin{aligned} & \text { Multiseriate } \\ & \text { rays }[1,2]\end{aligned}$

Bileşik öz 1şınları, Yalancı özışınları (aggregate rays), Bileşik (yalancı) öz 1şınları,
Hücre Aggregate rays $[1,2]$

\section{Tanım ve/veya terimin geçtiği cümle}

Homoselüler özışınları şekilleri birbirinin aynı olan hücrelerden yapılmıştır (Merev, 2003).

Öz 1şınları aynı büyüklük ve biçimdeki paranşim hücrelerini içeriyorsa homojen (homoselüler) öz ışını olarak tanımlanır (Erdin ve Bozkurt, 2013).

Heteroselüler özışınları da şekilleri birbirinden farklı olan hücrelerden yapılmıştır (Merev, 2003).

Öz 1şınları farklı büyüklük ve şekildeki paranşim hücrelerini içeriyorsa heterojen (heteroselüler) öz ışını olarak tanımlanır (Erdin ve Bozkurt, 2013).

Tek sıralı özışınlarına üniseri özışını denmektedir (Merev, 2003).

Dar, genellikle tek sıradan oluşmuş öz 1şınları tek sıralı öz ışını olarak adlandirilır (Erdin ve Bozkurt, 2013).

Mültiseri özışınlarının genişliği taksonlara göre 2-30 hücre arasında değişmektedir (Merev, 2003).

Çok sıralı öz 1şını genişliği birden fazla öz 1şının bir araya gelmesinden oluşan öz 1şınıdır (Erdin ve Bozkurt, 2013).

Bileşik öz ışınları; çok sayıda tek sıralı öz ışınının birbirine çok yakın bulunması nedeniyle makroskopik olarak geniş bir öz 1şını gibi değerlendirildiğ̣i, öz 1şını tipidir (Bozkurt ve Erdin, 1995).

Yalancı özışınları (aggregate rays); ikiden fazla üniseri veya biseri özışını arasına sadece lif ve paranşim hücrelerinin yerleşmesi ile olur (Merev, 2003).

Öz 1şınları, dar öz ışınlarının sık bir şekilde yan yana geldiği ve aralarında lifler, bazen de trahelerin bulunduğu bileşik (yalancı) öz 1şınları tipi vardır (Erdin ve Bozkurt, 2013).

\begin{tabular}{|c|c|c|c|}
\hline $\begin{array}{l}\text { Paralel kenar şeklinde } \\
\text { (rhombodial) } \\
\text { kristaller, } \\
\text { Rombodial kristaller }\end{array}$ & $\begin{array}{l}\text { Krista } \\
1\end{array}$ & $\begin{array}{l}\text { Prismatic } \\
\text { crystals } \\
\text { Syn. } \\
\text { Rhombodial } \\
\text { crystal [2] }\end{array}$ & $\begin{array}{l}\text { Rombodial kristaller; dört veya sekiz köşeli kalsiyum oksalattan } \\
\text { oluşmuş kristallerdir (Merev, 2003). } \\
\text { Paralel kenar şeklinde (rhombodial) kristaller; paralel kenar şeklinde } \\
\text { bulunan kristallerdir (Erdin ve Bozkurt, 2013). }\end{array}$ \\
\hline $\begin{array}{l}\text { Druz kristaller, } \\
\text { Kümeler halindeki } \\
\text { kristaller (druse), } \\
\text { Druz (küme şeklinde } \\
\text { kristal) }\end{array}$ & $\begin{array}{l}\text { Krista } \\
1\end{array}$ & Druses [1,2] & $\begin{array}{l}\text { Druz kristaller, uzamış birçok kristallerden oluşan, yıldız şeklinde } \\
\text { bir küme tipidir (Bozkurt ve Erdin, 1995). } \\
\text { Druz ( küme şeklinde kristaller) yıldız şeklinde olup yüzeyleri grintili } \\
\text { çıkıntılıdır (Merev, 2003). } \\
\text { Büyümüş hücreler içerisinde kümeler halinde bulunan kristaller } \\
\text { (druse) (Erdin ve Bozkurt, 2013). }\end{array}$ \\
\hline $\begin{array}{l}\text { Asikular kristaller, } \\
\text { İğne gibi tek tek } \\
\text { kristaller (acicular), } \\
\text { İğne şeklinde kristaller } \\
\text { (acicular crystals) }\end{array}$ & $\begin{array}{l}\text { Krista } \\
1\end{array}$ & $\begin{array}{l}\text { Acicular } \\
\text { crystals }[1,2]\end{array}$ & $\begin{array}{l}\text { Asikular kristaller, demet oluşturmayan iğne şeklindeki kristaller } \\
\text { olup, uzunlukları genişliklerinin } 10 \text { katı kadardır (Bozkurt ve Erdin, } \\
\text { 1995). } \\
\text { İğne şeklindeki kristaller (acicular crystals); çok ince ve çok küçüt } \\
\text { boyutlu kristallerdir (Merev, 2003). } \\
\text { Öz 1şınlarındaki kristaller iğne gibi tek tek (acicular) (Erdin ve } \\
\text { Bozkurt, 2013). }\end{array}$ \\
\hline $\begin{array}{l}\text { Rafidler, } \\
\text { Rafit, } \\
\text { İnce, uzun, iğne gibi } \\
\text { ve demet halinde } \\
\text { (raphides), }\end{array}$ & $\begin{array}{l}\text { Krista } \\
1\end{array}$ & $\begin{array}{l}\text { Raphid(e), } \\
\text { raphis, } \\
\text { pl. Raphides } \\
{[1,2]}\end{array}$ & $\begin{array}{l}\text { Rafidler; İğne şeklinde bir kristal demetidir (Bozkurt ve Erdin, } \\
\text { 1995). } \\
\text { Rafit; hücre içinde birçok ince ve uzun kristaller bir araya gelerek } \\
\text { demet şeklinde topluluk oluştururlar (Merev, 2003). } \\
\text { Öz 1şınlarındaki kristaller ince, uzun, iğne gibi ve demet halinde } \\
\text { (raphides) (Erdin ve Bozkurt, 2013). }\end{array}$ \\
\hline $\begin{array}{l}\text { Stiloid veya uzun } \\
\text { kristaller, Kalem } \\
\text { şeklinde kristal } \\
\text { (Styloid), }\end{array}$ & $\begin{array}{l}\text { Krista } \\
1\end{array}$ & Styloid $[1,2,3]$ & $\begin{array}{l}\text { Stiloid veya uzun kristaller; uçları sivri ya da kare kesitli, boyları } \\
\text { genişliklerinin en az } 4 \text { katı kadar olan büyük kristallerdir (Bozkurt } \\
\text { ve Erdin, 1995). } \\
\text { Kalem şeklinde kristal (Styloid); kristallerin uzunluğu genişliğinin } 4 \\
\text { katıdır, uçları düz veya sivridir (Merev, 2003). }\end{array}$ \\
\hline
\end{tabular}

IAWA, 1964 -[1]; IAWA, 1989 - [2]; IAWA, 2004 -[3]; FPL, 2010-[4] 
Çizelge 2. Farklı kaynaklarda kullanılmış harf farklilikları olan terimler

\begin{tabular}{cc}
\hline Terim 1 \\
$\begin{array}{c}\text { (Bozkurt, 1992; Bozkurt } \\
\text { ve Erdin, 1995; Bozkurt } \\
\text { ve Erdin, 2000; Erdin } \\
\text { ve Bozkurt, 2013) }\end{array}$ & Terim 2 \\
(Merev, 2003) \\
\hline Traheid & Traheit \\
\hline Tül & Til \\
\hline Öz 1şını & Özısısını \\
\hline Öz odun & Özodun \\
\hline Öz lekesi & Özlekesi \\
\hline İnisiyaller & İnisyaller \\
\hline Vaskular & Vasküler \\
\hline
\end{tabular}

\section{Değerlendirme ve Öneriler}

Ülkemizde odun anatomisi adı ile basılmış kitapların incelendiği bu çalışmada bir kavram için farklı kaynaklarda farklı terimlerin kullanıldığı görülmüştür. Tespit edilen toplam 70 terim içerisinde çevirisi yapıldığı dilden doğrudan alınan terimler, çevirisi yapılan dildeki terimin dilimizdeki söylenişi ile oluşturulan terimler veya çeviriyi yapanın uygun gördüğü kelime öbekleri şeklindeki terimler yer almaktadır. Tespit edilen terimler arasında 7 adet yazım farklıllğı görülen terimler ile karşılaşılmışır.

Terimlerin incelenmesi aşamasında karșılaşılan bir diğer sorun ise kavramların sınıflandırılması ve farklı terimler kullanılması olmuştur. Konuların anlatımında yazarlar sinıflandirmaları yaparken referans aldikları kaynakları kullandıkları için kaynaklarda sınıflandırmalarda farklılıklar görülmüştür. Sınıflandırmadaki farklılıklar neticesinde terimlerin kullanışında da farklılıklar gözlemlenmiştir. Sınıflandırmada ki bu karmaşa da mutlaka ayrı bir çalışma olarak değerlendirilmelidir.

Bu çalışmada karmaşa yaratan mevcut terimler tespit edilmiş ve ilgili bilim insanlarının dikkatini bu konu üzerine çekmek amaçlanmıştır. Terimlerdeki çeşitliliğin yol açabileceği sorunları çözmek adına ilgili bilim insanlarının bir araya gelerek yeni oluşumlar içerisine girmesi önerilir. Tekrardan kitap yazmak uzun vadeli ve oldukça karmaşık bir çözüm yolu olduğundan bu konu ile ilgilenen bilim insanları çalıştaylar düzenleyerek ortak terimlerin kullanımı için daha pratik ve daha hızlı bir çözüm üretme yoluna gidebilirler. Sonucunda ortak bir sözlük yazılarak hem bilimsel olarak çalışan bilim insanları hem de odun anatomisi konusunu öğrencilere aktaran öğretim üyeleri için faydalı bir kaynak oluşturulabilir. Doğru bilinen ve doğru kullanılan terimler sonucunda;

- Öğrencilerin odun anatomisi konularını kavraması kolaylaşacak,

- Bilimsel toplantılarda çalışmaların kolayca anlaşılması sağlanacak,

- Odun anatomisi konusunda mevcut bir konunun daha rahat bir şekilde tartışlması mümkün olacak,

- Akademik dergilerde gönderilen makalelerin değerlendirilme süreçlerinde çıabilecek karmaşa önlenmiş olacak,

- Akademik yükseltmelerde yapılan yazılı/sözlü sınavların ve çeşitli kurumlara sunulan bilimsel proje önerilerinin değerlendirilmesinde terimlerden kaynaklı anlaşmazlıklar giderilmiş olacaktır.

\section{Kaynaklar}

Bozkurt, A.Y., 1992. Odun Anatomisi. İstanbul Üniversitesi Orman Fakültesi Yayın No: 3652/415, Safya 293, İstanbul.

Bozkurt, Y. ve Erdin, N., 1995. İgne Yaprakl ve Yaprakh Ağaç Odunlarnda Tanm Özellikleri (Odun Anatomisi II). İstanbul Üniversitesi Yayin Nu:3907, Fen Bilimleri Enst. Yayın No:6, ISBN 975-404-406-6, Istanbul.

Bozkurt, Y. ve Erdin, E., 2000. Odun Anatomisi. İstanbul Üniversitesi Orman Fakültesi Yayın No 4263/466, s. 269.

Erdin, N. ve Bozkurt, Y., 2013. Odun Anatomisi. İstanbul Üniversitesi Yayın Nu:5145, OF Yayın No:506, ISBN 978-975-404-932-9, İstanbul.

Forest Product Laboratory, 2010. Wood Handbook -Wood as an Engineerin Material, General Technical Report FPL-GTR-190. Madison, WI: U.S. Department of Agriculture, Forest Service, Forest Products Laboratory.

IAWA Committee, 1964. Multilingual Glossary of Terms Used in Wood Anatomy. Verlagsanstalt Buchdruckerei Konkordia Winterthur.

IAWA Committee, 1989. IAWA List of Microscopic Features for Hardwood Identification. IAWA Bulletin, n.s. 10(3):332. 
IAWA Committee, 2004. IAWA List of Microscopic Features for Softwood Identification. $L A W A$ Journal, 25 (1): 1-70.

Merev, N., 2003. Odun Anatomisi. Karadeniz Teknik Üniversitesi Orman Fakültesi, Genel yayın Nu: 209, Fakülte yayın No:31, ISBN 975-6983-29-9, Trabzon.
TDK Yayınları, 2011. Türkçe Sö₹lük, Türk Tarih Kurumu Basımevi; Ankara. 508 p.

Yumru, D., 2010. Terim Üret(me)me Sorunu. Cukurova Üniversitesi Eğitim Fakültesi Dergisi, 3(39):10-19.

Zülfikar, H., 1991. Terim Sorunlar ve Terim Yapma Yollar, Ankara: TDK Yayınları. 